\title{
THROMBOPLASTIC FACTORS IN PLATELETS AND RED BLOOD CELLS: OBSERVATIONS ON THEIR CHEMICAL NATURE AND FUNCTION IN IN VITRO COAGULATION *
}

\author{
By STANLEY B. TROUP, CLAUDE F. REED, GUIDO V. MARINETTI AND \\ SCOTT N. SWISHER

\begin{abstract}
(From the Departments of Medicine and Biochemistry, The University of Rochester School of Medicine and Dentistry, Rochester, N. Y.)
\end{abstract}

(Submitted for publication August 7, 1959; accepted October 16, 1959)

Although the existence of blood platelets had been known for many years it was not until 1882 that Bizzozero (1) called attention to the role of platelets in blood coagulation. Morawitz (2), twenty years later, was among the first to consider the specific chemical contribution of the platelet to the clotting process.

Howell (3), in 1912, demonstrated the presence of an unsaturated phosphatide ("kephalin") in thromboplastic substances of tissue origin. Mills (4), in 1927, showed cephalin to be present in blood platelets, and the following year Haurowitz and Sládek (5) published results of chemical analysis of horse platelets, reporting a lipid content of 12 per cent of dry weight. The first convincing data relating the cephalin content of platelets to acceleration of coagulation were supplied by Chargaff, Bancroft and Stanley-Brown (6). These workers also reported at that time what has recently been emphasized again $(7,8)$ : phosphatides from other natural sources (soy bean, yeast) also were capable of accelerating blood clotting in vitro. Erickson, Williams, Avrin and Lee (9), confirmed the results of Chargaff and associates relating to platelet phospholipid content. Wallach, Surgenor and Steele (10), identified phosphatidyl ethanolamine and phosphatidyl serine in human platelets. Subsequently the presence of inositol phosphatide was noted $(11,12)$.

Wooldridge, in 1886 (13), demonstrated a coagulant effect of substances obtained from red cells by both aqueous and lipid solvents. With small doses of these extracts administered intravenously to dogs, Wooldridge also observed a hypocoagulable

\footnotetext{
* These studies were supported by a contract with the Research and Development Division, Office of the Surgeon General, Department of the Army (DA-49-007-MD-632), and a grant $(\mathrm{H}-4167)$ from the National Heart Institute, Bethesda, Md.
}

state similar to that noted in animals infused with thromboplastin (14-16). Much more recently a number of investigators $(11,17-21)$, have again demonstrated active coagulant substances in red cell hemolysates or extracts. Further studies have demonstrated that the coagulant activity resides in a lipoprotein $(22,23)$ or a lipid (11). The exact chemical nature of these thromboplastic substances derived from platelets and red blood cells has been the subject of much investigation since Wooldridge's publication (13). That the primary coagulant activity resides in the cephalin fraction was shown by the work of a number of investigators $(3,24$ $27)$ in the period between 1886 and 1930. In 1921, Zunz and LaBarre (28) demonstrated that an excess of cephalin inhibited coagulation and that lecithin, inactive alone (27), potentiated the effects of cephalin in combination. Folch (29), in 1942, demonstrated that brain cephalin is in fact a mixture of phosphatidyl serine, phosphatidyl ethanolamine, and inositol phosphatide. Since then much effort has been directed toward the identification of the specific phospholipid compounds in platelets responsible for the platelet contribution to coagulation. Results pertinent to this problem have frequently been in disagreement. O'Brien (30) called attention to the similarity in coagulant activity of platelets and phosphatidyl ethanolamine; Poole and Robinson $(31,32)$ supported the view that phosphatidyl ethanolamine could accelerate thrombin generation in plasma, but were unable to demonstrate this thrombingenerating activity by phosphatidyl serine or lecithin. Barkhan, Newlands and Wild (33), working with Folch fractions of human brain, also demonstrated clot-accelerating activity by phosphatidyl ethanolamine, and found phosphatidyl serine to be inhibitory. Rapport (34), on the other hand, using phosphatidyl serine obtained by 
Folch fractionation of brain lipids, reported that addition of lecithin to phosphatidyl serine resulted in acceleration of clotting. Biggs and Bidwell (35) could not correlate the clotting activity of Folch brain fractions with their phosphatidyl ethanolamine content or with their content of any other phospholipid compound. O’Brien (36) later concluded that the clotting activity of one phospholipid may be influenced by the presence of another phospholipid, for he found coagulant activity in a mixture of phosphatidyl serine with inositol phosphatide, as well as in a mixture with phosphatidyl ethanolamine.

A preliminary communication from this laboratory (11) reported that phosphatidyl serine displayed the most potent coagulant activity of all the platelet or red cell phosphatides and that this activity was much enhanced by the addition of lecithin. Coagulant activity was also demonstrable in mixtures of phosphatidyl ethanolamine and lecithin. or phosphatidyl ethanolamine and sphingomyelin. Phospholipids similarly isolated from human red blood cells had activity identical to those obtained from human platelets. Therriault, Nichols and Jensen $(37,38)$, using brain phospholipid, demonstrated marked coagulant activity of phosphatidyl serine and lecithin when mixed first in chloroform solution, but no activity of either compound alone. Marcus and Spaet (39) have also recently confirmed the coagulant activity of phosphatidyl serine obtained from human platelets. Rouser, White and Schloredt $(40,41)$ have emphasized the importance of fatty acid unsaturation in active coagulant phospholipids, and have concluded that phosphatidic acid and phosphatidyl ethanolamine are the active platelet phospholipids. Turner, Silver, Tocantins and Holburn $(42,43)$ have attributed an antithromboplastic activity to phosphatidyl serine but, more recently, Barkhan, Silver, daCosta and Tocantins (44) have reported that phosphatidyl serine can act as an accelerator or as an inhibitor of coagulation depending upon the experimental conditions. This possibility had been predicted by Wolf (45), based on observations by Overman (46).

It is thus apparent that the role of platelet phospholipids in coagulation has not been precisely defined. Incleed, the lipid content of human platelets has not been accurately characterized or quantified. The development of more refined techniques for characterizing phospholipids (47) and the successful application of these techniques to red cell lipids (48) suggested application of the same methods to human platelet lipids. The present studies have attempted to identify and quantify the lipids of normal human platelets, to assess the role of these platelet lipids in the in vitro coagulation process, and to compare the effects of platelet lipids and the red cell lipids in similar in vitro coagulation systems.

\section{MATERIALS AND METHODS}

A. Isolation of platelets from whole blood. Blood was obtained from normal adult volunteers; it was collected by gravity flow into plastic bags containing 1.5 per cent disodium dihydrogen ethylenediaminetetraacetate in 0.7 per cent $\mathrm{NaCl}^{1}{ }^{1}$ employing a plastic donor set. ${ }^{2}$ A proportion of 9 volumes of blood to 1 volume of anticoagulant was used. Forty $\mathrm{ml}$ aliquots were then gently decanted into silicone-coated ${ }^{3}$ glass tubes and these were centrifuged at room temperature at $300 \mathrm{G}$ for $15 \mathrm{~min}$ utes. All glasswerare used in collection and transfer of platelet-containing plasma was similarly treated. All glassware used in the coagulation studies was acidcleaned. The supernatant platelet-rich plasma was transferred by pipette to glass centrifuge tubes. Aliquots of platelet-rich plasma were then taken for platelet and white cell counting, and aliquots to be used in coagulation studies were stored at $4^{\circ} \mathrm{C}$ in glass tubes. The platelet-rich plasma thus obtained had fewer than 300 leukocytes per $\mathrm{cu} \mathrm{mm}$, and was completely free of red cells. The platelet-rich plasma was then centrifuged at $2,000 \mathrm{G}$ at $4^{\circ} \mathrm{C}$. The supernatant platelet-poor plasma thus obtained was decanted into other centrifuge tubes and again centrifuged at $4^{\circ} \mathrm{C}$ for 30 minutes at $2,000 \mathrm{G}$. This supernatant plasma had fewer than 1,000 platelets per cu mm (49) and was considered to be "plateletpoor." The sedimented platelets obtained after the first $2,000 \mathrm{G}$ centrifugation were pooled and washed 3 times with isotonic $\mathrm{NaCl}$ solution and resedimented by centrifugation at $4^{\circ} \mathrm{C}$ for 5 minutes at $900 \mathrm{G}$. The platelets thus obtained were then subjected to lipid extraction and analysis.

B. Extraction, scparation, and measurement of platelet and red cell lipids. The methods used for the extraction, separation, and quantification of the red cell lipids were those previously employed (48). The chromatographic methods of lipid separation have been described in detail by Marinetti, Erbland and Kochen (47). The washed platelets were extracted 3 times with $30 \mathrm{ml}$ of chloroformmethanol $(1: 1)^{4}$; the platelet residue was separated by

\footnotetext{
1 EDTA Platelet Pack, Fenwal Laboratories, Inc.

2 Plexitron, Baxter Laboratories, Inc.

3 Dowex-Corning Fluid 200.

${ }^{4}$ All solvents were Mallinckrodt, redistilled, reagent
} grade. 
centrifugation and the supernatants were pooled and evaporated to complete dryness under partial vacuum with a nitrogen atmosphere. The residue of the pooled supernatant was re-extracted with $30 \mathrm{ml}$ of chloroform: this extract was filtered through fritted glass, evaporated to dryness and constant weight under partial vacuum and a nitrogen atmosphere, and the lipids weighed. The entire extraction procedure was carried out at $37^{\circ} \mathrm{C}$. The lipids were then dissolved in sufficient benzene to achieve a concentration of 5 to $10 \mathrm{mg}$ per $\mathrm{ml}$. Total lipid phosphorus, using the method of Berenblum and Chain (50) was determined on aliquots of this solution. The total cholesterol content was determined by the method of Bloor (51). The phospholipids were separated on silicic acid-impregnated paper in a solvent system consisting of 2.6-dimethyl heptanone-4, n-butyl ether, acetic acid, and water in the ratio of $20: 20: 22: 3.3$. The chromatograms were developed by ascending chromatography at $20^{\circ} \mathrm{C}$ for 16 hours. After drying, the individual lipid spots were identified with rhodamine $6 \mathrm{G}$ under ultraviolet light; the lipid phosphorus was eluted with $1 \times \mathrm{HCl}$ in methanol at $64^{\circ} \mathrm{C}$ with mechanical shaking, and the net amount of phosphorus from each lipid spot was determined. Net phosphorus recoveries ranged from 94 to 101 per cent of the total phosphorus applied to the chromatogram.

Chromatographically-pure individual phospholipids were obtained by partially separating the total lipid extract by silicic acid column chromatography, as described by Marinetti and associates. The fraction containing the desired phospholipid was rechromatographed on silicic acid-impregnated paper which had been washed by descending chromatography for 8 days. The washing was performed successively with methanol, methanol: chloroform $(1: 1), 0.01 \mathrm{~N} \mathrm{NH} \mathrm{N}_{4} \mathrm{OH}, 0.5$ per cent ethylenediaminetetraacetic acid (EDTA) and distilled water, and was designed to remove any elutable impurities from the paper. Multiple adjacent spots of origin were used in applying the lipid to the paper. The chromatographic strip ascending from a laterally placed spot was cut from the paper bearing the multiple spots and stained with rhodamine $6 \mathrm{G}$ dye. The stained strip was used to locate the individual lipid which was then cut free. The unstained phospholipid was eluted from the paper, using methanol: chloroform $(4: 1)$ at $37^{\circ} \mathrm{C}$ during a $15 \mathrm{~min}$ ute period. The eluate was evaporated to dryness under partial vacuum and nitrogen atmosphere. The dried eluate was re-extracted with chloroform and rechromatographed on a $1 \mathrm{~g}$ silicic acid column. Ten $\mathrm{ml}$ of chloroform, followed by $5 \mathrm{ml}$ of 10 per cent methanol in chloroform was passed through the column to elute impurities carried over from the paper. The remaining phospholipid was then eluted with $10 \mathrm{ml}$ of methanol.

The phospholipid separation was confirmed by paper chromatography: a sufficient amount of lipid was chromatographed to exclude contamination of more than 3 per cent by phospholipids other than the one being isolated. Phosphatidyl serine was obtained in amounts sufficient to determine its phosphorus content by weight, which was found to be 3.63 per cent. The phosphorus content by weight of mixtures of phosphatidyl serine and phosphatidyl ethanolamine obtained directly from partial fractionation of the total lipid mixture by column chromatography ranged from 3.60 to 3.65 per cent. The weight of lipid employed in subsequent coagulation studies was calculated from the lipid phosphorus, assuming a phosphorus content of 3.63 per cent.

C. Coagulation studies. The coagulant activity of the various phospholipids was assayed by measuring the effect of the lipid on prothrombin conversion during plasma clotting, and by measuring the effect of added lipids on "thromboplastin generation" employing a modification of the test described by Biggs and Douglas (52). The effect of lipid on prothrombin conversion was tested in the following manner. The specific prothrombin concentration of the normal platelet-poor plasma, prepared as described above, was determined by the modification of the one-stage method of (Owren (53) as described by Alexander (54). One $\mathrm{ml}$ of platelet-poor plasma was allowed to clot by addition of $0.2 \mathrm{ml}$ of $0.025 \mathrm{M} \mathrm{CaCl}$. () ne hour after clotting, serum was obtained by centrifugation at $900 \mathrm{G}$ for 5 minutes. The specific prothrombin concentration of the serum obtained was determined and considered to be the control value. The lipid to be tested was then emulsified by stirring it in $1 \mathrm{ml}$ of platelet-poor plasma with a glass rod for 1 minute: this plasma was then allowed to clot by addition of $0.2 \mathrm{ml}$ of $0.025 \mathrm{M}$ $\mathrm{CaCl}_{2}$. One hour after clotting the serum was again obtained, and the specific prothrombin concentration was determined. Prothrombin content of the serum from the untreated plasma and from the various lipid-plasma test mixtures was expressed as percentage of the prothrombin content of the original platelet-poor plasma.

The normal control thromboplastin generation test of Biggs and Douglas (52) was carried out with platelets. aluminum hydroxide-treated plasma, and serum obtained from the blood of normal volunteers. The test was then performed omitting the normal platelet suspension, and this was considered to be the "test control." The tests of lipids were then performed, without the normal platelet suspension, and with the lipid to be tested emulsified with a glass stirring rod for 1 minute in aluminum hydroxide-treated plasma. The remainder of the test procedure was as outlined by Biggs and Douglas.

\section{RESULTS}

\section{A. Lipid analy'ses of normal platelets and red} cells. Table I summarizes the results of the analyses of the lipids extracted from normal human platelets and from normal human red cells. The amount of each phospholipid was calculated from its analytical phosphorus content, assuming the phosphorus content of the lipids to be 3.7 per cent. The platelet lipid analyses were performed 10 times on platelets from 10 different normal subjects. The red cell lipid analyses were carried out 
TABLE I

Average composition of total cell lipid

\begin{tabular}{lcc}
\hline & $\begin{array}{c}\text { Red blood } \\
\text { cell }\end{array}$ & Platelet \\
\hline & $\%$ & $\%$ \\
Cholesterol & 23 & 19 \\
Phosphatidyl ethanolamine & 17 & 17 \\
Phosphatidyl serine & 11 & 6 \\
Lecithin & 22 & 32 \\
Sphingomyelin & 16 & 13 \\
Inositol phosphatide & 3 & 5 \\
Other lipids & 8 & 8 \\
\hline
\end{tabular}

more than 20 times; detailed results of these analyses have been published elsewhere (48).

The similarity in composition of the lipids of the red cells and of the platelets is apparent. The proportion of phospholipid in each case is just less than 70 per cent of the total lipids. The red cell lipids contain significantly more phosphatidyl serine, and less lecithin, than do the platelet lipids. The lipids grouped into "others" include a small amount of lyso-lecithin, glycolipids, traces of free fatty acids, neutral fats, and cholesterol esters.

The lipids of human plasma have been studied employing similar techniques, and will be reported elsewhere (55). We have been unable to identify any phosphatidyl serine in fasting normal human plasma that had been gathered with care to avoid red cell and platelet lysis while being rendered cell- and platelet-free. Efforts to demonstrate phosphatidyl serine in such plasma have included in vivo $\mathrm{P}^{32}$-labeling of the plasma lipids, and concentration of lipids from large volumes of plasma.

Figure 1 is an autoradiograph of the chromatographically separated phospholipids from the platelets of a patient given $\mathrm{P}^{32}$. Figure 2 is a photograph of the chromatographic separation of the lipid extracted from normal red cells and from normal platelets. The chromatographically pure compounds present in the chromatograms in Figure 2 were obtained as described in Methods.

Approximately $1 \mathrm{mg}$ of lipid was consistently obtained from the platelets present in $10 \mathrm{ml} \mathrm{sam}$ ples of normal whole blood. This is approximately seven times the quantity found by Marcus and Spaet (39). This difference can best be attributed to differences in techniques of collecting and processing the platelets. By performing platelet counts (49) on the whole blood and on the platelet-rich

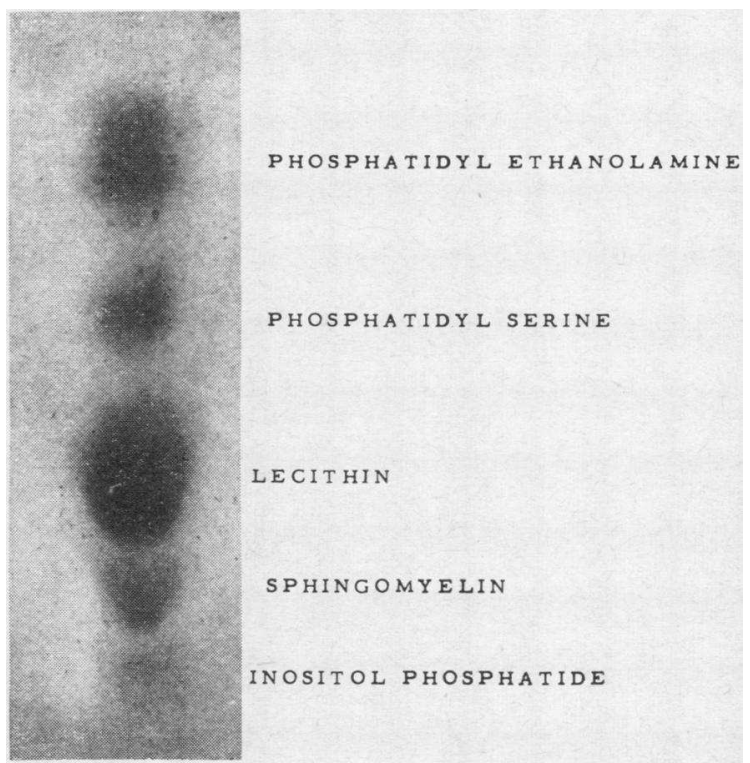

Fig. 1. Segment of autoradiogram of chromatoGRAPHICALLY SEPARATED PLATELET PHOSPHOLIPID. The platelets were labeled in vivo by administration of $5 \mathrm{mc}$ of $\mathrm{P}^{32}$ to an adult male with polycythemia vera. The blood from which the platelet lipid was extracted was withdrawn seven days after the $\mathrm{P}^{32}$ administration; $500 \mu \mathrm{g}$ of lipid was applied to the chromatogram.

plasma obtained from that whole blood, it was evident that approximately 80 per cent of the platelets initially present in the whole blood were obtained for the lipid extraction and analysis. Thus, approximately $1.25 \mathrm{mg}$ of platelet lipid is actually present in $10 \mathrm{ml}$ of whole blood. By comparison, the red cells of $10 \mathrm{ml}$ of normal whole blood contain approximately $26 \mathrm{mg}$ of lipid.

$B$. In vitro effect of lipids on coagulation. Figure 3 summarizes the results of a typical series of in vitro coagulation experiments. The serum derived from the clotting of platelet-poor plasma without added lipid contained 90 per cent of the prothrombin initially present in the plasma. Plasma to which $5 \mu \mathrm{g}$ of complete platelet or red cell lipid had been added yielded serum containing less than 15 per cent of the plasma prothrombin. The clotting of platelet-rich plasma also yielded serum containing about 15 per cent of the prothrombin initially present in the plasma. Adding $5 \mu \mathrm{g}$ of phosphatidyl serine to platelet-poor plasma resulted in serum containing only small amounts of prothrombin. The platelets present in $1 \mathrm{ml}$ of normal whole blood contain approximately $5 \mu \mathrm{g}$ of phosphatidyl serine. No other single lipid 


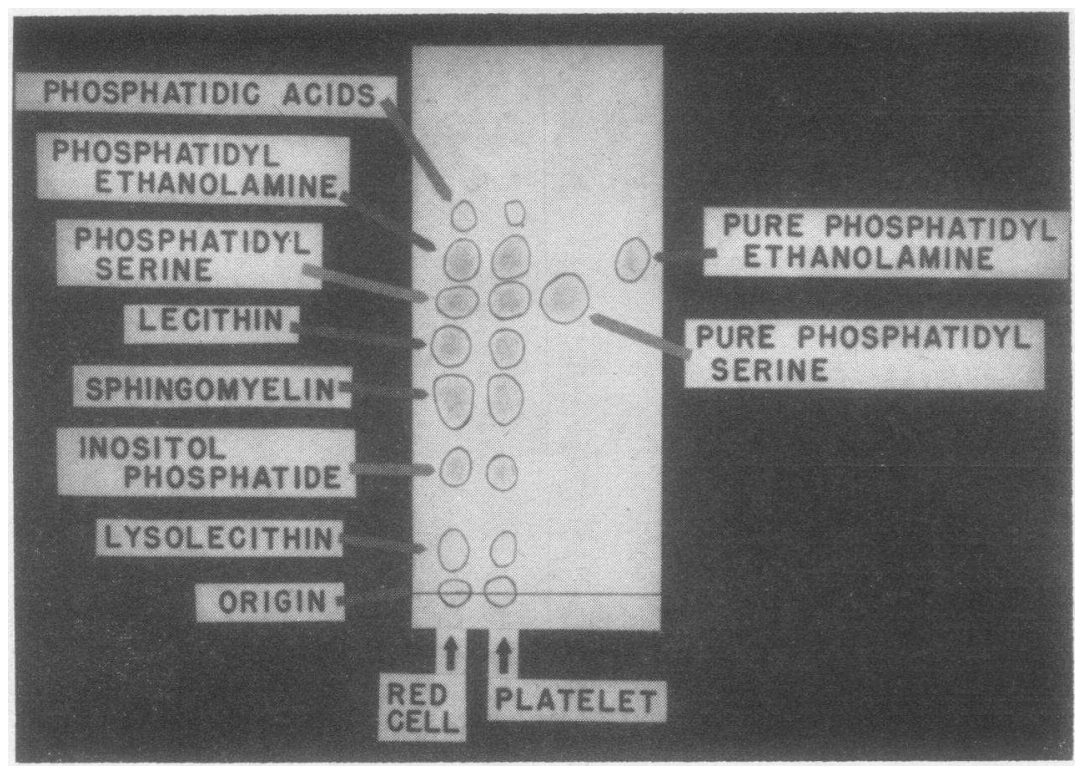

Fig. 2. Chromatographic separation of phospholipids. The front of the chromatogram is at the top of the paper. Staining is with rhodamine 6G. Compounds labeled as pure are chromatographically pure. The spot identified as phosphatidic acids is a mixture of polyglycerophosphatides, which include phosphatidic acids.

produced an equivalent consumption of prothrombin, even when added to the test system in amounts approximating or exceeding their representation in viv'o. Lipid compounds not listed in Figure 3, such as cholesterol and inositol phosphaticle, failed to result in any prothrombin consumption in this test system.

Figure 4 illustrates typical tests of combinations of lipids which, when tested individually, were

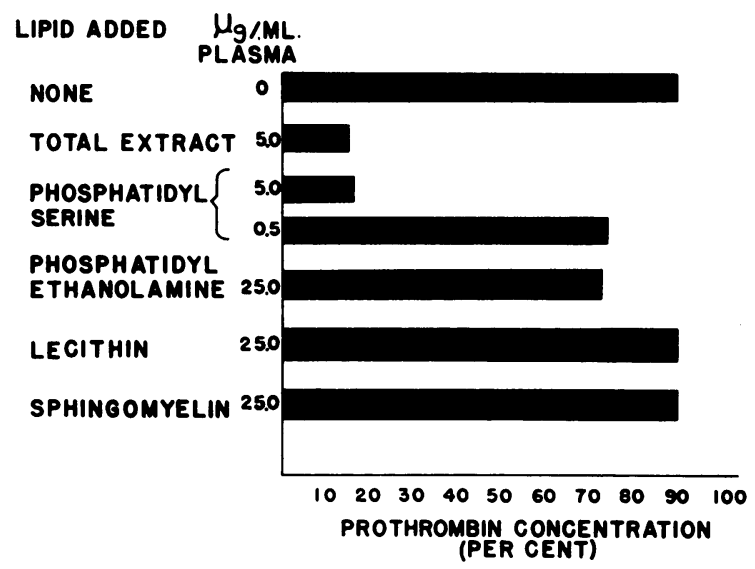

Fig. 3. Serum prothrombin concentration. The serum was obtained one hour after the clotting of a recalcified mixture of platelet-poor plasma and the indicated lipid. either inactive or less active than when combined with other lipids as indicated. All possible combinations of the six major lipid compounds isolated were tested, employing a wide quantitative range both above and below the normal in wivo concentrations of these materials in the platelets of whole blood. Results similar to those illustrated in Figures 3 and 4 were obtained when lipids isolated from multiple samples of either platelets or red cells were tested. For example, when three separate highly purified samples of phosphatidyl serine derived from different lipid extracts were tested for their ability to influence prothrombin consumption, the range of residual serum prothrombin was from 5 to 17 per cent. The residual serum prothrombin in simultaneous tests of all other platelet phospholipids invariably exceeded 70 per cent.

It is noteworthy that the combination of phosphatidyl serine and lecithin, each in concentrations ineffective singly, when combined, equaled the activity of $5 \mu \mathrm{g}$ of the complete lipid (Figure 3 ). The quantities of phosphatidyl serine and lecithin listed in Figure 4 are those amounts present in $5 \mu \mathrm{g}$ of complete platelet lipid extract. Thus, it is possible that the activity of the complete platelet lipid can be explained by its content of phosphatidyl serine and lecithin alone. 
Phosphatidyl ethanolamine and sphingomyelin, each found to be inactive alone, clearly enhanced prothrombin consumption when they were combined. The amounts of these two lipids present in $5 \mu \mathrm{g}$ of complete platelet lipid, when tested together, showed only minimal activity. Phosphatidyl ethanolamine and lecithin also exhibited some activity when combined, but this was less than the activity of the combination of phosphatidyl ethanolamine and sphingomyelin. No other lipid combinations demonstrated any activity in this test system.

The coagulant activity of the lipids was also assessed, employing our modification of the thromboplastin generation test. Figure 5 illustrates representative results. The control generating mixture contained no lipid in the $\mathrm{Al}(\mathrm{OH})_{3}$-treated plasma.

Maximal activity was produced by the phosphatidyl serine-lecithin mixture. The amount of each lipid used was equivalent to that present in $2 \mu \mathrm{g}$ of complete platelet lipid. It was repeatedly demonstrated that phosphatidyl serine alone, of all the individual lipids, would result in thromboplastic activity when added to the generating mixture. Phosphatidyl ethanolamine failed to perform in a manner significantly different from the lipid-free control in all instances.

Lipids obtained from red cells and platelets were chemically modified in several ways and their effect on prothrombin consumption was subsequently tested. The alterations produced in separate lipid samples were: 1 ) saturation of the



Fig. 4. Serum prothrombin concentration. The serum was obtained one hour after the clotting of a recalcified mixture of platelet-poor plasma and the indicated lipid combinations.

double bonds with hydrogen, 2) hydroxylation and epoxylation of the fatty acid double bonds, and 3) acylation of the free amino groups. Each of these changes rendered the lipids inactive in these test systems, while the unmodified lipids produced great activity when equivalent amounts were tested.

Several synthetic phospholipids were also tested. ${ }^{5}$ These were: 1) phosphatidyl seryl glycyl glycine, an analog of phosphatidyl serine, in which two molecules of glycine are present in a peptide linkage at the usual position of the single serine molecule; 2) dioleyl phosphatidyl ethanolamine, in which both fatty acid groups are oleic acid; and 3 )

5 Provided by Dr. E. Baer, Department of Biochemistry University of Toronto, Canada.

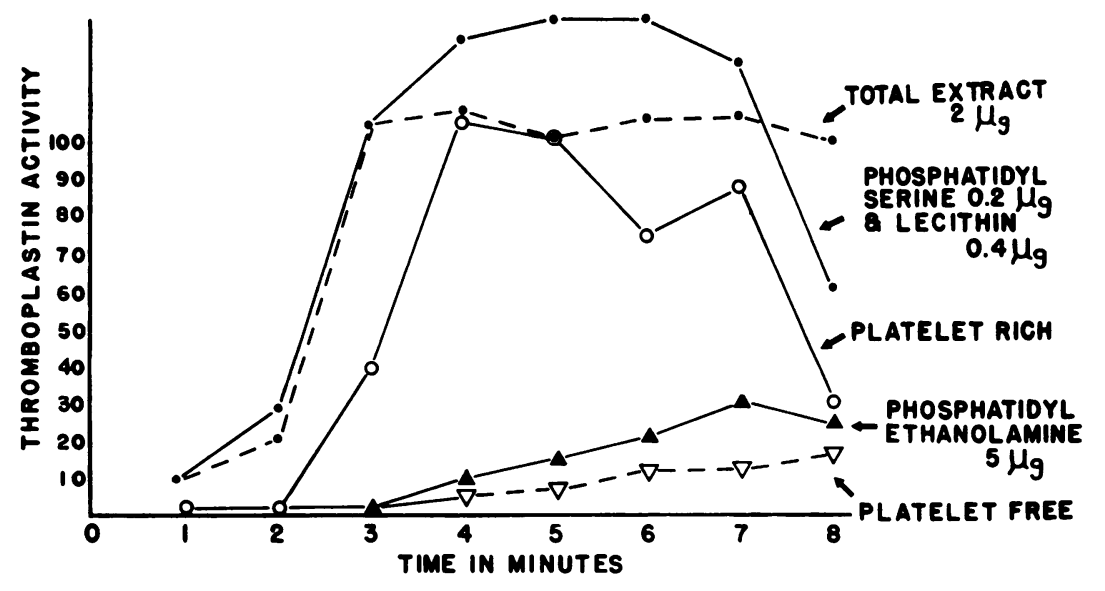

Fig. 5. Thromboplastin generation. The test was modified from that of Biggs and Douglas (52). The indicated lipids were substituted for the usual platelet suspension. 
distearyl phosphatidyl ethanolamine, in which both fatty acids are stearic acid. None of the synthetic lipids displayed any activity in this test system.

\section{DISCUSSION}

The observations reported here confirm the presence of a variety of phosphatides including phosphatidyl ethanolamine, phosphatidyl serine, lecithin, sphingomyelin, and inositol phosphatide in human platelets. Cholesterol constitutes a significant portion of the platelet lipids, but only a very small amount is present as cholesterol ester, free fatty acids, neutral fat, or lysolecithin.

Of particular interest is the presence in platelets of phosphatidyl serine, which appears to be uniquely a cellular phospholipid. It has not been possible to identify phosphatidyl serine by any method in normal human plasma gathered with care to avoid platelet or red cell lysis. Studies utilizing isotopic labeled lipids (55) have also been unable to detect phosphatidyl serine in cell-free plasma. Phosphatidyl ethanolamine, however, and each of the other cellular lipids, can be identified in normal cell-free human plasma. Axelrod, Reichenthal and Brodie (56) have reported small amounts of phosphatidyl serine in two samples of human plasma, but they did not indicate whether the plasma samples were first rendered cell- and platelet-free.

At least $100 \mu \mathrm{g}$ of platelet lipid is present in 1 $\mathrm{ml}$ of normal human whole blood. Five $\mu \mathrm{g}$ of platelet lipid furnishes, in vitro, sufficient coagulant activity to generate maximally the thromboplastin in $2.0 \mathrm{ml}$ of reaction mixture (52) or to activate the prothrombin in $1 \mathrm{ml}$ of platelet-poor plasma. It thus seems likely that there is normally an excess of both plasma and platelet coagulant factors.

Although there has been general agreement that the platelet contribution to coagulation is at least partly phospholipid in nature $(30-33,35,36,39$ $42,44,45)$, there has been no unanimity of opinion as to whether this is a single lipid compound (35). The data presented here suggest that one phospholipid, phosphatidyl serine, is the most potent phospholipid in the coagulation process. The activity it possesses is potentiated by, but is not dependent upon, lecithin. Thus, the same activity attributed to $5 \mu \mathrm{g}$ of complete platelet lipid in the prothrombin consumption or thromboplastin generation tests can be achieved by the use of a combination of phosphatidyl serine and lecithin only, equal to the amounts in the $5 \mu \mathrm{g}$ of the complete lipid. None of the other lipids, singly or in combination as they are represented in the complete lipid extract, demonstrated equivalent activity. The potentiation by lecithin of the coagulant effect of phosphatidyl serine has been reported by others $(34,37-39)$. The data presented here, however, differ from those reported by Therriault, Nichols and Jensen $(37,38)$. They demonstrated a coagulant effect of phosphatidyl serine and lecithin, but demonstrated no coagulant effect for phosphatidyl serine alone.

Phosphatidyl ethanolamine and sphingomyelin, and to a lesser degree, phosphatidyl ethanolamine and lecithin, potentiate the clotting mechanism as measured in our test systems but require concentrations that greatly exceed those found in normal human platelets.

The similarity in lipid content of human platelets and red blood cells was shown in Table I. Similarity in coagulant activity of the lipids was also shown. Equal amounts of the complete lipid, extracted from red cells or from platelets, demonstrated equivalent activity in both the prothrombin consumption and thromboplastin generation tests. The separated lipids from platelets and red cells also behaved similarly in the clotting tests. These data cannot be construed, however, as evidence for the identity of chemical composition of the lipids obtained from platelets and from red cells.

The red cells of $1 \mathrm{ml}$ of whole blood contain enough lipid to activate the prothrombin of at least $1,500 \mathrm{ml}$ of normal plasma. Although it is unlikely that all of this lipid in the red cells becomes available for thromboplastin formation upon intravascular erythrocyte destruction, it is possible that the lipid liberated by intravascular hemolysis may be related to the bleeding (57) and clotting $(19,58-61)$ disorders that frequently accompany such processes.

The chemical characteristics that endow certain of the phospholipids with coagulant activity and deprive other phospholipids of this activity are not known. The importance of unsaturation in active lipids was first noted by Howell (3). McLean (25) correlated the coagulant activity of lipids with their degree of unsaturation. This concept 
has been emphasized more recently by Rouser, White and Schloredt $(40,41)$ who also emphasized the importance of a free amino group on the coagulant phospholipids. Our data suggest that the degree of unsaturation alone is inadequate to explain the coagulant activity of the active phospholipids. When the active phospholipid compounds were saturated with hydrogen without altering free amino groups, all coagulant activity disappeared. The saturated phospholipids are less soluble than the unsaturated phospholipids, and it might be reasoned that the loss of coagulant activity is associated with phospholipid insolubility. However, acylation of the free amino groups, without altering the unsaturation, also completely destroyed the coagulant effect of previously active phospholipids. Acylation, it should be noted, does not alter the phospholipid solubility. Thus, solubility alone would not seem an adequate explanation for differences in phospholipid coagulant activity. The failure of the synthetic phosphatides tested to demonstrate coagulant activity is also unexplained.

A number of investigators have utilized nonpolar solvents to combine various phosphatides in vitro $(34,37,38)$. We have not found it necessary to employ a nonpolar solvent to produce effective combinations of lecithin and phosphatidyl serine. The potentiating effect of lecithin occurs if the phosphatides are combined and emulsified in normal saline or in plasma. The phospholipids used by some of these workers $(34,37,38)$ were obtained from animal brains. The phospholipids used in our experiments were obtained from human platelets and red cells, and it is possible that species differences account for some of the differences in findings. The observations reported here are difficult to reconcile with those reported earlier $(30-33,40-43)$, in which a coagulant role has been assigned to phosphatidyl ethanolamine and an anticoagulant effect to phosphatidyl serine.

Species differences in chemical composition of the phospholipids may exist. It seems wise to compare results with this in mind. Within the same species, tissue differences in chemical composition of the phospholipids may also occur. We have felt that the phospholipids derived from blood cells and platelets offered the best material for such studies. The methods of separating and purifying the phospholipids in such studies are of great importance. Because of the powerful coagulant effect of the active lipid materials, the Folch fractionation technique (29) seems inadequate for lipid separation for these purposes. Paper chromatographic techniques seem to offer the best methods currently available for resolving phospholipid mixtures. Even with these methods, contamination of one phospholipid with amounts of another sufficient to obscure results in coagulation tests may occur. For example, contamination of less than 3 per cent of phosphatidyl serine in a phosphatidyl ethanolamine preparation may not be detectable by chromatographic techniques. If $20 \mu \mathrm{g}$ of such a contaminated phosphatidyl ethanolamine preparation is then tested for its coagulant effect, sufficient phosphatidyl serine will be present to yield substantial coagulant activity.

Finally, methods of testing the various phospholipids for this coagulant effect are of great importance. It is well established that an excess of phospholipid can interfere with an early phase of coagulation $(28,45)$. Accordingly, it would seem wise to test these phospholipids in vitro within the range of their probable physiological representation.

\section{SUMMARY AND CONCLUSIONS}

1. The phospholipids of human platelets have been identified and measured, utilizing a refined chromatographic technique. Platelet phospholipids were found to be very similar to the phospholipids of human red cells.

2. Within the limits of resolution of the chromatographic system, it is clear that only one phospholipid, phosphatidyl serine, which is present in both platelet and red cells, but not in plasma, was able to substitute for the whole platelet lipid extract in the two in vitro coagulation systems used in these studies.

3. The coagulant activity of phosphatidyl serine was enhanced by the presence of lecithin.

4. Phosphatidyl ethanolamine, inactive alone in the test system employed, displayed some coagulant activity when combined with lecithin, and a lesser activity when combined with sphingomyelin.

5. The coagulant activity of the complete platelet lipid extract could be reproduced by employing only the amounts of phosphatidyl serine and lecithin contained in the whole lipid extract. 


\section{REFERENCES}

1. Bizzozero, J. Ueber einen Formbestandtheil des Blutes und dessen Rolle bei der Thrombose und der Blutgerinnung. Virchow's Arch. path. Anat. 1882, 90, 261.

2. Morawitz, P. Beiträge zur Kenntnis der Blutgerinnung. 2. Mitteilung. Dtsch. Arch. klin. Med. 1904, $79,215$.

3. Howell, W. H. The nature and action of the thromboplastic (zymoplastic) substance of the tissues. Amer. J. Physiol. 1912, 31, 1.

4. Mills, C. A. The role of the platelets in blood clotting. Chinese J. Physiol. 1927, 1, 235.

5. Haurowitz, F. and Sládek, J. Über die chemische Zusammensetzung der Blutplättchen. Hoppe-Seylers Z. physiol. Chem. 1928, 173, 233.

6. Chargaff, E., Bancroft, F. W., and Stanley-Brown, M. Studies on the chemistry of blood coagulation. III. The chemical constituents of blood platelets and their role in blood clotting, with remarks on the activation of clotting by lipids. J. biol. Chem. 1936, 116, 237.

7. White, S. G., Lagen, J. B., Aggeler, P. M., and Geyer, R. P. Effect of soybean phosphatide on blood coagulation defect following total body $\mathrm{X}$-irradiation in the dog. Proc. Soc. exp. Biol. (N. Y.) 1953, 83, 384.

8. Newlands, M. J., and Wild, F. Sources of platelet factor for the thromboplastin generation test. $\mathrm{Na}$ ture (Lond.) 1955, 176, 885.

9. Erickson, B. N., Williams, H. H., Avrin, I., and Lee, P. The lipid distribution of human platelets in health and disease. J. clin. Invest. 1939, 18, 81 .

10. Wallach, D. F. H., Surgenor, D. M., and Steele, B. B. Calcium-lipid complexes in human platelets. Blood 1958, 13, 589.

11. Troup, S. B., and Reed, C. F. Platelet thromboplastic factor: Its chemical nature, in vitro activity, and the identification of similar thromboplastic substances in red blood cells (abstract). J. clin. Invest. 1958, 37, 937.

12. Marcus, A. J., and Spaet, T. H. Chromatographic studies on platelet phospholipids. Clin. Res. 1958, 6, 199.

13. Wooldridge, L. C. Über intravasculäre Gerinnungen. Arch. Physiol. (Lpz.) 1886, Physiol. Abthg., 397.

14. Hartmann, R. C., Conley, C. L., and Krevans, J. R. The effect of intravenous infusion of thromboplastin on "heparin tolerance." J. clin. Invest. 1951, $30,948$.

15. Penick, G. D., Roberts, H. R., Webster, W. P., and Brinkhous, K. M. Hemorrhagic states secondary to intravascular clotting. An experimental study of their evolution and prevention. Arch. Path. 1958, 66, 708.

16. Wooldridge, L. Zur Chemie der Blutkörperchen. Arch. Physiol. (Lpz.) 1881, Physiol. Abthg., 387.

17. Shinowara, G. Y. Enzyme studies on human blood.
XI. The isolation and characterization of thromboplastic cell and plasma components. J. Lab. clin. Med. 1951, 38, 11.

18. Gollub, S. Thromboplastic potency of whole blood components. Fed. Proc. 1953, 12, 54.

19. Quick, A. J., Georgatsos, J. G., and Hussey, C. V. The clotting activity of human erythrocytes. Theoretical and clinical implications. Amer. J. med. Sci. 1954, 228, 207.

20. Leupold, R. Zur thromboplastischen Wirkung der Erythrocyten. Schweiz. med. Wschr. 1955, 85 911.

21. Dreskin, O. H. Prothrombin measurement by twostage technique with hemolyzed whole blood thromboplastin. J. Lab. clin. Med. 1958, 51, 312.

22. Shinowara, G. Y. Thromboplastic cell component, the lipoprotein of erythrocytes and platelets. J. biol. Chem. 1957, 225, 63.

23. Penner, J. A., Duckert, F., Johnson, S. A., and Seegers, W. H. Conversion of prothrombin to autoprothrombin, II. Canad. J. Biochem. 1956, 34, 1199.

24. McLean, J. The thromboplastic action of cephalin. Amer. J. Physiol. 1916, 41, 250.

25. McLean, J. The relation between the thromboplastic action of cephalin and its degree of unsaturation Amer. J. Physiol. 1917, 43, 586.

26. Gratia, A., and Levene, P. A. The role of cephalin in blood coagulation. J. biol. Chem. 1922, 50, 455.

27. Wadsworth, A., Maltaner, F., and Maltaner, E. Further studies of the chemical reactions underlying the coagulation of the blood. The activity of lecithin. Amer. J. Physiol. 1930, 91, 423.

28. Zunz, E., and LaBarre, J. Recherches sur l'action des phosphatides dans la coagulation du sang. Archiv. int. Physiol. 1921, 18, 116.

29. Folch, J. Brain cephalin, a mixture of phosphatides. Separation from it of phosphatidyl serine, phosphatidyl ethanolamine, and a fraction containing an inositol phosphatide. J. biol. Chem. 1942, 146, 35 .

30. O'Brien, J. R. The similarity of the action of phosphatidyl-ethanolamine and platelets in blood coagulation. J. clin. Path. 1956, 9, 47.

31. Poole, J. C. F., and Robinson, D. S. A comparison of the effects of certain phosphatides and of chylomicra on plasma coagulation in the presence of Russell's vipor venom. Quart. J. exp. Physiol. 1956, 41, 31.

32. Robinson, D. S., and Poole, J. C. F. The similar effect of chylomicra and ethanolamine phosphatide on the generation of thrombin during coagulation. Quart. J. exp. Physiol. 1956, 41, 36.

33. Barkhan, P., Newlands, M. J., and Wild, F. Phospholipids from brain tissue as accelerators and inhibitors of blood coagulation; preliminary communication. Lancet 1956, 2, 234.

34. Rapport, M. M. Activation of phospholipid thromboplastin by lecithin. Nature (Lond.) 1956, 178, 591. 
35. Biggs, R., and Bidwell, E. An attempt to identify a single phospholipid active in blood coagulation. Brit. J. Haemat. 1957, 3, 387.

36. O'Brien, J. R. The effect of some fatty acids and phospholipids on blood coagulation. Brit. J. exp. Path. 1957, 38, 529.

37. Therriault, D. G., and Nichols, T. Purification and identification of brain phospholipids associated with thromboplastic activity. Fed. Proc. 1958, 17, 322.

38. Therriault, D., Nichols, R., and Jensen, H. Purification and identification of brain phospholipides associated with thromboplastic activity. J. biol. Chem. 1958, 233, 1061.

39. Marcus, A. J., and Spaet, T. H. Platelet phosphatides: Their separation, identification, and clotting activity. J. clin. Invest., 1958, 37, 1836.

40. Rouser, G., White, S. G., and Schloredt, D. Phospholipid structure and thromboplastic activity. I. The phosphatide fraction active in recalcified normal human plasma. Biochim. biophys. Acta 1958, 28, 71.

41. Rouser, G., and Schloredt, D. Phospholipid structure and thromboplastic activity. II. The fatty acid composition of the active phosphatidyl ethanolamines. Biochim. biophys. Acta 1958, 28, 81.

42. Turner, D. L., Silver, M. J., and Tocantins, L. M. Phospholipid antithromboplastin. Fed. Proc. 1958, $17,164$.

43. Holburn, R. R., Silver, M. J., Turner, D. L., and Tocantins, L. M. Phospholipid antithromboplastin: Studies on mechanism of action. Fed. Proc. 1958, 17, 244.

44. Barkhan, P., Silver, M. J., daCosta, P. B., and Tocantins, L. M. Phosphatidyl serine and blood coagulation. Nature (Lond.) 1958, 182, 1031.

45. Wolf, P. Lipid extracts of platelets and brain as substitutes for platelets in coagulation tests. Brit. J. Haemat. 1956, $2,375$.

46. Overman, R. S. The chemical purification and mode of action of thromboplastic inhibitor. Transactions of Second Conference on Blood Clotting and Allied Problems. New York, Josiah Macy, Jr. Foundation, 1949, p. 29.

47. Marinetti, G. V., Erbland, J., and Kochen, J. Quantitative chromatography of phosphatides. Fed. Proc. 1957, 16, 837.

48. Reed, C. F., Eden, E., Marinetti, G. V., and Swisher,
S. N. Studies of erythrocyte phospholipids. I. J. Lab. clin. Med. In press.

49. Brecher, G., Schneiderman, M., and Cronkite, E. P. The reproducibility and constancy of the platelet count. Amer. J. clin. Path. 1953, 23, 15.

50. Berenblum, I., and Chain, E. An improved method for the colorimetric determination of phosphate. Biochem. J. 1938, 32, 295.

51. Bloor, W. R. The determination of cholesterol in blood. J. biol. Chem. 1916, 24, 227.

52. Biggs, R., and Douglas, A. S. The thromboplastin generation test. J. clin. Path. 1953, 6, 23.

53. Owren, P. A. New clotting factors. Transactions of Fifth Conference on Blood clotting and Allied Problems. New York, Josiah Macy, Jr. Foundation, 1952, p. 92.

54. Alexander, B. One stage method for specific prothrombin determination (in the plasma or serum) in The Coagulation of Blood. Methods of Study, L. M. Tocantins, Ed. New York, Grune and Stratton, 1955, p. 94.

55. Reed, C. F. Studies of erythrocyte phospholipids II. Their exchange with plasma phospholipids. In preparation.

56. Axelrod, J., Reichenthal, J., and Brodie, B. B. The direct determination of phosphatidyl ethanolamine and phosphatidyl serine in plasma and red blood cells. J. biol. Chem. 1953, 204, 903.

57. Krevans, J. R., Jackson, D. P., Conley, C. L., and Hartmann, R. C. The nature of the hemorrhagic disorder accompanying hemolytic transfusion reactions in man. Blood 1957, 12, 834.

58. Crosby, W. H., and Rappaport, H. Autoimmune hemolytic anemia. I. Analysis of hematologic observations with particular reference to their prognostic value. A survey of 57 cases. Blood 1957, $12,42$.

59. Rappaport, H., and Crosby, W. H. Autoimmune hemolytic anemia. II. Morphologic observations and clinicopathologic correlations. Amer. J. Path. 1957, 33, 429.

60. Crosby, W. H., and Dameshek, W. Paroxysmal nocturnal hemoglobinuria. The mechanism of hemolysis and its relation to the coagulation mechanism. Blood 1950, 5, 822.

61. Troup, S. B., Swisher, S. N., and Young, L. E. Unpublished observations. 